\title{
PEMBELAJARAN KOOPERATIF DENGAN PENDEKATAN NUMBERED HEAD TOGETHER (NHT) DAN MOTIVASI BELAJAR TERHADAP HASIL BELAJAR SISWA
}

\author{
Abd. Fatah \\ Guru Matematika SMKN I Sampang \\ Email: fatahaldi7@gmail.com
}

\begin{abstract}
Abstrak:
Tujuan Penelitian ini adalah : 1) Untuk mengetahui perbedaan hasil belajar yang ditunjukkan oleh siswa yang belajar dengan menggunakan model kooperatif tipe NHT dan pembelajaran konvensional terhadap hasil belajar siswa SMK di Sampang pada pokok bahasan matematika keuangan (anuitas). 2) erbedaan hasil belajar yang ditunjukkan oleh siswa yang mempunyai motivasi belajar tinggi dengan siswa yang mempunyai motivasi belajar rendah terhadap hasil belajar siswa SMK di Sampang pada pokok bahasan anuitas. 3) Untuk mengetahui interaksi antara penggunaan model pembelajaran kooperatif tipe NHT dan pembelajaran konvensional, serta motivasi siswa terhadap hasil belajar siswa SMK di Sampang pada pokok bahasan anuitas. Jenis penelitian ini adalah eksperimen dengan subjek penelitian siswa kelas XII ,instrumennya adalah tes dan kuesioner. Homogenitas subjek penelitian diuji dengan independent sample test. Normalitas data diuji dengan one sample kolmogorovSmirnov. Pengujian hipotesis menggunakan two way anova dengan menampilkan nilai rata-rata dari statistic deskriptif sebagai tingkat pembeda. Berdasarkan hasil penelitian dapat disimpulkan bahwa : 1) Ada perbedaan hasil belajar yang ditunjukkan oleh siswa yang belajar dengan menggunakan model kooperatif tipe NHT dan pembelajaran konvensional yang diterima dengan tingkat signifikansi $0,000(<0,05)$. Mean tertinggi terdapat pada model pembelajaran tipe NHT yang secara total diperoleh hasil sebesar 89,27. 2). Ada perbedaan hasil belajar yang ditunjukkan oleh siswa yang mempunyai motivasi belajar tinggi dengan siswa yang mempunyai motivasi belajar rendah yang diterima dengan tingkat signifikansi $0,000(<0,05)$. Mean tertinggi terdapat pada motivasi belajar tinggi yang secara total diperoleh hasil sebesar 88,84. 3) Ada interaksi yang signifikan antara model pembelajaran tipe NHT, konvensional dan motivasi belajar terhadap hasil belajar siswa pada pokok bahasan anuitas yang diterima pada tingkat signifikansi $0,001 \quad(<0,05)$. Sedangkan mean tertinggi terdapat pada interaksi antara model pembelajaran tipe NHT dengan motivasi belajar sebesar 89,74.
\end{abstract}

Kata Kunci: NHT, Motivasi Belajar, Hasil Belajar Matematika

\begin{abstract}
:
The objectives of this study are: 1) To determine the differences in learning outcomes shown by students who learn using the NHT-type cooperative model and conventional learning on the learning outcomes of vocational school students in Sampang on the subject of financial mathematics (annuity). 2) the difference in learning outcomes shown by students who have high learning motivation with students who have low learning motivation towards learning outcomes of vocational school students in Sampang on the subject of annuity. 3) To determine the interaction between the use of the cooperative learning model type NHT and conventional learning, as well as student motivation on learning outcomes of vocational students in Sampang on the subject of annuity. This type of research is an experiment with research subjects of class XII students, the instruments are tests and questionnaires. The homogeneity of the research subjects was tested by using the independent sample test. Data normality was tested with one sample Kolmogorov-Smirnov. Hypothesis testing uses two way ANOVA by displaying the average value of descriptive statistics as a level of differentiation. Based on the results of the study it can be concluded that: 1) There are differences in learning outcomes shown by students who learn using the NHT type cooperative model and accepted conventional learning with a significance level of $0.000(<0.05)$. The highest mean is found in the NHT type learning model which in total obtained results of 89.27.
\end{abstract}


2). There are differences in learning outcomes shown by students who have high learning motivation with students who have low learning motivation who are accepted with a significance level of $0.000(<0.05)$. The highest mean is found in high learning motivation, which in total is 88.84. 3) There is a significant interaction between the NHT type learning model, conventional and learning motivation on student learning outcomes on the subject of annuities received at a significance level of $0.001(<0.05)$. While the highest mean is found in the interaction between the NHT type learning model with learning motivation of 89.74 .

Keywords: NHT, Learning Motivation, Mathematics Learning Outcomes

\section{Pendahuluan}

Menyadari peranannya yang semakin penting, pendidikan matematika perlu mengantisipasi tantangan masa depan yang semakin rumit dan kompleks (Simbolon, 2019). Karena itu pendidikan matematika harus mampu membekali siswa keterampilan yang dapat menjawab permasalahan mendatang. Berbagai upaya dan daya dalam meningkatkan kemampuan matematika siswa telah dilakukan oleh berbagai pihak (Lanya, dkk, 2020). Namun upaya dan daya itu belum sesuai dengan tujuan yang diharapkan. Kenyataan di lapangan menunjukkan adanya kesenjangan sangat besar antara kenyataan dengan hasil yang diharapkan. Rendahnya mutu pendidikan di Indonesia merupakan masalah klasik yang sering kali dibahas dalam berbagai lokakarya, seminar-minar lokal atau seminar-minar nasional.

Rendahnya mutu pendidikan matematika mungkin disebabkan oleh kegiatan pembelajaran yang dilaksanakan di sekolah selama ini lebih berorientasi pada guru. Maksudnya siswa dalam kegiatan pembelajaran hanya berperan sebagai pendengar dan pencatat sehingga siswa bersifat pasif (Qulsum, 2020). Siswa seharusnya dituntut untuk berperan aktif dan saling berinteraksi untuk mengkonstruksi, menemukan dan mengembangkan kemampuannya serta mengungkapkan dalam bahasanya sendiri tentang pengetahuan yang diterima dan diolah selama pembelajaran berlangsung (Syarifah, 2015).

Pembelajaran matematika dengan menggunakan sistem latihan, menghafal dan pemberian tugas, tidak jarang digunakan namun pembelajaran matematika tersebut, akan lebih efektif apabila siswa dilibatkan secara aktif selama proses pembelajaran (Zayyadi, 2016). Pendekatan struktural ada dua jenis, yaitu Think Pair Share (TPS) dan Numbered Head Together (NHT). Dalam penelitian ini, peneliti hanya membahas pendekatan struktural jenis NHT karena jenis NHT memiliki prosedur yang ditetapkan secara eksplisit untuk lebih banyak memberi kesempatan kepada siswa dalam berpikir, menjawab, dan saling membantu satu dengan yang lain (Arends, 2001).

Pembelajaran matematika di SMK harus disesuaikan dengan tujuan pembelajaran yang terdapat dalam Kurikulum 2013 Matematika SMK. Pembelajaran matematika agar lebih bermanfaat bagi siswa, maka perlu ditekankan relevansinya dengan kehidupan sehari-hari (Zayyadi \& Maulana, 2016). Dengan kata lain adalah siswa diharapkan lebih berminat belajar matematika. Oleh karena itu guru sebaiknya membuat persiapan yang tertata sehingga siswa memperoleh pengalaman belajar yang beragam dan fungsional.

Tujuan penelitian ini adalah untuk mengetahui pengaruh pembelajaran kooperatif dengan pendekatan struktural Numbered Heads Together (NHT) dan motivasi belajar terhadap hasil belajar untuk pokok bahasan anuitas di kelas XII AK SMKN 1 Sampang dan kelas XII AK SMKN 1 Tambelangan.

\section{Metode Penelitian}

Penelitian ini pada dasarnya penelitian kuantitatif eksperimen kuasai dengan pre test, post test pada kelompok ekuivalen. Adapun jenis rancangan analisis penelitian yang digunakan adalah factorial design $2 \times 2$. Variabel bebas penelitian yakni model pembelajaran dengan dimensi Numbered Head Together (NHT) dan 
variabel moderator ada 2 yakni motivasi belajar tinggi dan motivasi belajar rendah. Variabel terikatnya adalah hasil belajar siswa dalam mata pelajaran matematika. Lokasi penelitian ini adalah di SMKN 1 Sampang. Sedangkan subyek penelitiannya siswa kelas XII AK 1 sebagai kelas kontrol, dan kelas XII AK 2 untuk eksperimen yang sedang mengikuti mata pelajaran matematika, dan lokasi penelitian di SMKN 1 Tambelangan subyek penelitiannya adalah kelas XII AK 1 sebagai kelas kontrol, dan kelas XII AK 2 untuk uji coba instrumen, kelas-kelas tersebut akan dijadikan kelompok penelitian sesuai dengan rancangan penelitian di atas.

Ada 2 macam instrument yang digunakan dalam penelitian ini yaitu instrumen untuk intervensi dan instrumen untuk mengukur hasil belajar. Instrumen yang pertama terdiri dari instrumen untuk : penyelenggaraan aktivitas Numbered Head Together dan pembelajaran konvensional sebagai panduan aktivitas untuk pembelajaran dikelas.instrumen yang kedua meliputi : (1) angket, yang meliputi motivasi belajar tinggi dan motivasi belajar rendah, (2) tes hasil belajar matematika, instrumen penelitian ini sebelum digunakan dalam penelitian ini akan dilakukan uji instrumen validitas dan reliabilitas.

Sumber data dalam penelitian adalah subyek dimana data dapat di peroleh Maka sumber data dalam penelitian ini meliputi hasil belajar siswa dan hasil angket motivasi. Teknik pengumpulan data di lakukan dengan kuesioner (angket) dan data tentang hasil belajar siswa diperoleh dari hasil penilaian tertulis.

Analisis data yang digunakan dalam penelitian ini adalah analisis varian dua faktor, bantuan program SPSS 16 . Analisis varian dua faktor digunakan untuk mengetahui pengaruh dua faktor $\mathrm{A}$ dan $\mathrm{B}$ pada suatu respon/variabel, serta untuk mengetahui apakah terdapat interaksi yang signifikan antara kedua faktor. Hal ini menggunakan rancangan ANAVA dua jalur.

\section{Hasil dan Pembahasan}

Arends (1997) menjelaskan bahwa pendekatan struktural adalah salah satu pendekatan pembelajaran kooperatif, guru menggunakan struktur tertentu agar pola interkasi siswa lebih kooperatif dan berbagi. Lebih lanjut Arends menjelaskan bahwa dalam pendekatan struktural (Prastiwi, 2015), tim mungkin bervariasi dari 2 sampai 6 anggota dan struktur tugas mungkin ditekankan pada tujuan-tujuan sosial atau akademik.

Arends (1997) menjelaskan ada dua macam struktur yang terkenal yaitu ThinkPair Share (TPS) dan Numbered-Heads Together (NHT), yang dapat digunakan oleh guru untuk mengajarkan isi akademik atau mengecek pemahaman siswa terhadap isi tertentu. Sedangkan "active listening" dan "time token" merupakan dua contoh struktur yang dikembangkan untuk mengajarkan keterampilan sosial.

Dalam tulisan ini, peneliti hanya membahas pendekatan struktural Numbered Heads Together (NHT). Hal itu disebabkan pendekatan struktural Numbered Heads Together (NHT) yang dieksperimenkan dalam penelitian ini. Ibrahim (2000) mengemukakan tiga tujuan yang akan dicapai dalam pembelajaran kooperatif tipe NHT yaitu: a) hasil belajar akademik struktural, bertujuan untuk meningkatkan kinerja siswa dalam tugas- tugas akademik; b) pengakuan adanya keragaman, bertujuan agar siswa dapat menerima temantemannya yang mempunyai berbagai latar belakang; c) pengembangan keterampilan sosial, bertujuan untuk mengembangkan keterampilan sosial siswa.

Arend (1997) menjelaskan bahwa Numbered Heads Together adalah salah satu jenis pendekatan struktural, setiap anggota kelompok diberi nomor (label) untuk mempelajari suatu materi pelajaran. Lebih lanjut Arends (1995: 326) menyatakan bahwa, Numbered-Heads Together (NHT) adalah suatu pendekatan yang dikembangkan untuk memberikan kesempatan lebih banyak kepada siswa dalam menelaah materi yang tercakup dalam suatu pelajaran dan mengecek pemahaman mereka terhadap isi pelajaran tersebut.

Empat langkah pokok pembelajaran kooperatif struktural Numbered Heads Together (NHT) di atas, penulis 
menjabarkan kegiatan pembelajaran

kooperatif struktural NHT. Kegiatan

Numbered Heads Together (NHT) dapat pembelajaran kooperatif struktural

dilihat pada tabel berikut ini.

\section{Tabel 1. Langkah-langkah Kegiatan Pembelajaran Kooperatif dengan Pendekatan} Struktural NHT

\begin{tabular}{lc}
\hline \multicolumn{1}{c}{ Kegiatan Pembelajaran } & Langkah NHT \\
\hline \multicolumn{1}{c}{ Pendahuluan } \\
a setiapali dengan membagi siswa ke dalam kelompok (4-6) dan & Langkah 1 \\
b Menginformasikan materi yang akan dibahas. & Penomoran \\
c Menyampaikan tujuan pembelajaran dan pendekatan & \\
d Membelajaran yang akan digunakan. & \\
\hline
\end{tabular}
Kegiatan Inti

a Mengajukan pertanyaan secara klasikal.

Langkah 2

mengajukan pertanyaan

Langkah 3

b Memikirkan pertanyaan yang diajukan oleh guru.

berpikir bersama

Menyatukan pendapat dengan cara mengerjakan tugas yang

c diberikan, dan memastikan setiap anggota kelompok mengetahui jawabannya.

Guru memanggil salah satu label dari kelompok tertentu secara

$\mathrm{d}$ acak, siswa yang dipanggil mengacungkan tangan, dan menjawab pertanyaan yang diajukan oleh guru.

Langkah 4

menjawab

Siswa label sama (kelompok lain) menanggapi, guru memimpin

e diskusi.

f Guru memberikan pujian kepada kelompok (individu) yang

menjawab benar.

Memberi kesempatan kepada siswa mencatat jawaban yang

$\mathrm{g}$ benar.

\begin{tabular}{l}
\hline \multicolumn{1}{c}{ Penutup } \\
\hline a Memberi umpan balik \\
b Membimbing siswa menyimpulkan materi. \\
c Memberi kuis dan PR.
\end{tabular}

Berdasarkan uraian di atas, ada 1) Melibatkan siswa lebih banyak dalam beberapa alasan peneliti memilih pendekatan dalam menelaah materi. Pada saat guru struktural Numbered Heads Together (NHT) mengajukan pertanyaan ke seluruh kelas, sebagai berikut: masingmasing anggota kelompok memiliki kesempatan yang sama untuk mewakili kelompok dalam menyampaikan hasil diskusi kelompok melalui pemanggilan label anggota kelompok secara acak Artinya wakil kelompok yang menyampaikan hasil diskusi kelompok tidak hanya terfokus pada siswa yang lebih pandai atau didasarkan kesepakatan kelompok. Tetapi semua siswa mempunyai kesempatan untuk mewakili kelompok, tanpa dibeda-bedakan. 2) Tidak terlalu banyak kelompok, sehingga bila ingin mengecek pemahaman seluruh siswa tidak perlu terlalu banyak menunjukkan (memanggil) label siswa. Satu label siswa dapat mewakili satu kelompok. 3) Akibat dari tidak perlunya menunjukkan banyak label siswa, maka tidak terlalu banyak memakan waktu untuk mengecek pemahaman siswa. Artinya dimungkinkan waktu lebih efisien daripada think pair share. 
Pengertian Anuitas

Pernahkah anda menghitung sendiri cicilan yang harus dibayar setiap bulan jika akanmembeli rumah dengan cara angsuran? Dapatkah anda menghitung sisa pinjamananda, jika sudah mencicil selama $\mathrm{n}$ tahun dari pembayaran rumah yang anda cicil? Itusemua akan di bahas dalam kompetensi dasar Anuitas.

Anuitas adalah sejumlah pembayaran pinjaman yang sama besarnya yang dibayarkansetiap jangka waktu tertentu, dan terdiri atas bagian bunga dan bagian angsuran.

Anuitas $=$ Angsuran + Bunga $A=a n+b n$

Untuk $\mathrm{n}=$ bilangan asli: $1.2 .3 \ldots$

Jika suatu pinjaman sebesar $\mathrm{M}$ dilunasi dengan sistem anuitas tahunan selama $\mathrm{n}$ tahun dengan suku bunga i\%/tahun, dan setiap anuitas sama besarnya, maka berlaku: $\mathrm{An}+1=\mathrm{An}$

an $+1+b n+1=a n+b n$

an $+1=$ an + bn - bn +1

an $+1=$ an + an. $\dot{i}$

an $+1=$ an $(1+i)$, sehingga:

$\mathrm{a} 1=\mathrm{a} 1(1+\mathrm{i})$.

$\mathrm{a} 3=\mathrm{a} 2(1+\mathrm{i})$.

$\mathrm{a} 3=\mathrm{a} 1(1+\mathrm{i})(1+\mathrm{i})$.

$\mathrm{a} 3=\mathrm{a} 1(1+\mathrm{i})^{2}$

$\mathrm{a} 4=\mathrm{a} 3(1+\mathrm{i})$.

$\mathrm{a} 4=\mathrm{a} 1(1+\mathrm{i})^{2}(1+\mathrm{i})$.

$\mathrm{a} 4=\mathrm{a} 1(1+\mathrm{i})^{3}$, dan seterusnya.

Sehingga diperoleh rumus:

an $=\mathrm{a} 1(1+\mathrm{i}) \mathrm{n}-1$ atau an $=\mathrm{ak}(1+\mathrm{i}) \mathrm{n}-\mathrm{k}$

Perbedaan Hasil Belajar

Matematika Antara yang Menggunakan Model Pembelajaran Kooperatif tipe NHT dan Pembelajaran Konvensional.

Dari analisis yang telah dilakukan perhitungan anava dua jalur dengan bantuan program SPSS Release 12 yang terlihat pada Tabel 4.3 dapat diketahui bahwa hipotesis pertama yang peneliti ajukan diterima atau didukung, hal ini terbukti dengan nilai $\mathrm{F}$ hitung sebesar 23,576 > F tabel $(3,9087)$ dan nilai signifikan sebesar 0,000 dimana kurang dari 0,05 (5\%), sehingga dapat dikatakan terdapat perbedaan hasil belajar antara yang menggunakan model pembelajaran kooperatif tipe NHT dan pembelajaran konvensional pada mata pelajaran matematika siswa kelas XII AK di SMKN 1
Sampang dan SMKN 1 Tambelangan. Ini menunjukan bahwa antara model pembelajaran kooperatif tipe NHT dan tipe Konvensional mempunyai dampak yang berbeda terhadap hasil belajar dari masingmasing siswa. Dari hasil penelitian tersebut diperoleh rerata skor hasil belajar matematika kelompok siswa yang mengikuti pembelajaran konvensional adalah 83,13 . Sedangkan rerata skor hasil belajar matematika kelompok siswa yang mengikuti pembelajaran NHT adalah 89,27. Dari data tersebut dapat disimpulkan bahwa rerata skor hasil belajar kelompok siswa yang mengikuti pembelajaran konvensional lebih tinggi daripada rerata skor hasil belajar siswa yang mengikuti pembelajaran kooperatif tipe NHT.

Dengan demikian penerapan pembelajaran kooperatif tipe NHT merupakan salah satu alternatif model pembelajaran yang efektif untuk meningkatkan hasil belajar matematika untuk kompetensi dasar anuitas. Hal ini juga sesuai dengan hasil penelitian Solekhah \& Murdiana (2015) penerapan model pembelajaran kooperatif tipe NHT dapat meningkatkan hasil belajar siswa melalui fase menyampaikan tujuan dan memotivasi siswa, fase menyajikan informasi, fase penomoran, fase mengajukan pertanya- an, fase berpikir bersama, fase menjawab (evaluasi), dan fase memberikan penghargaan.

Perbedaan hasil belajar matematika siswa yang mempunyai motivasi tinggi dan motivasi rendah. Untuk hipotesis kedua yang peneliti ajukan juga di dukung atau terbukti kebenarannya, hal ini terbukti dengan nilai $\mathrm{F}$ hitung sebesar 19,769 > F tabel $(3,9087)$ dan nilai signifikan sebesar 0,000 dimana kurang dari 0,05 (5\%), sehingga dapat dikatakan bahwa terdapat perbedaan hasil belajar antara siswa yang mempunyai motivasi tinggi dan motivasi rendah pada mata pelajaran matematika siswa kelas XII di SMKN 1 Sampang dan SMKN 1 Tambelangan. Dari hasil penelitian diperoleh rerata skor hasil belajar siswa yang memiliki motivasi belajar rendah yang mengikuti model pembelajaran Konvensional adalah 78,75 dan rerata skor hasil belajar kelompok siswa yang memiliki 
motivasi belajar tinggi adalah 87,95. Sedang rerata skor hasil belajar siswa yang memiliki motivasi belajar rendah yang mengikuti model pembelajaran NHT adalah 89,05 dan rerata skor hasil belajar kelompok siswa yang memiliki motivasi tinggi adalah 89,74.Dari rerata skor hasil belajar untuk siswa yang memiliki motivasi belajar rendah dan siswa yang memiliki motivasi belajar tinggi, siswa yang mengikuti pembelajaran dengan menggunakan model NHT lebih tinggi dari pada siswa yang mengikuti pembelajaran dengan menggunakan model Konvensional. Interaksi antara model pembelajaran Konvensional dan tipe NHT dan motivasi terhadap hasil belajar matematika Untuk hipotesis yang ketiga yang peneliti ajukan juga diterima atau terbukti kebenarannya hal ini terbukti dengan nilai $\mathrm{F}$ hitung sebesar 11,956 > F tabel $(3,9087)$ dan nilai signifikan sebesar 0,001 dimana kurang dari 0,05 (5\%), hal ini menunjukkan bahwa terdapat interaksi antara model pembelajaran kooperatif tipe NHT, Konvensional dan motivasi terhadap hasil belajar pada mata pelajaran matematika siswa kelas XII SMKN 1 Sampang dan SMKN 1 Tambelangan. Hal ini sesuai dengan penelitian Mardyastuti, dkk (2016) bahwa terdapat interaksi antara model pembelajaran kooperatif tipe NHT, Konvensional dan motivasi terhadap hasil belajar. Selain itu Terdapat perbedaan hasil belajar IPA antara siswa yang dibelajarkan melalui model pembelajaran Kooperatif Tipe Numbered Head Together (NHT) dan siswa yang dibelajarkan melalui model pembelajaran konvensional (Santhi, dkk, 2017). Ini menunjukkan bahwa perpaduan antara model pembelajaran dan motivasi mempunyai dampak yang baik terhadap hasil belajar siswa. Selain model pembelajaran yang tepat, guru juga harus dapat memberikan motivasi kepada siswa, karena motivasi mempunyai peranan dan manfaat yang sangat penting dalam keberhasilan belajar yang dilakukan oleh siswa, semakin tinggi motivasi belajar yang dimiliki individu, semakin tinggi pula hasil belajar yang dicapai.

\section{Simpulan dan Saran Simpulan}

Berdasarkan hasil pengujian hipotesis dikaitkan dengan interprestasi dari pembahasan hasil penelitian, maka dapat disimpulkan sebagai berikut :

1. Terdapat perbedaan hasil belajar matematika antara siswa yang menggunakan model pembelajaran kooperatif tipe NHT dan pembelajaran konvensional.

2. Terdapat perbedaan hasil belajar matematika siswa yang mempunyai motivasi tinggi dan motivasi rendah.

3. Terdapat interaksi antara model pembelajaran kooperatif tipe NHT, pembelajaran konvensional dan motivasi terhadap hasil belajar matematika siswa.

\section{Saran}

Berdasarkan simpulan tersebut, saran-saran yang dapat diajukan adalah

1. Pemberian model pembelajaran kooperatif dipandang perlu karena dapat membantu siswa dalam mencapai hasil belajar matematika yang diharapkan terutama pada mata pelajaran matematika karena trebukti baik secara teoritis maupun empiris seperti yang telah ditunjukkan oleh penelitian ini.

2. Model pembelajaran tidak akan berhasil jika tidak di dukung dengan motivasi belajar dari siswa, oleh karena itu pihak guru diharapkan untuk lebih dapat meningkatkan motivasi belajar siswa. Guru diharapkan kreatif, inovatif dalam proses belajar mengajar, sehingga motivasi belajar siswa tidak berkurang.

3. Disarankan kepada siswa agar selalu belajar dengan konservatif agar memperoleh hasil belajar yang lebih optimal, hal ini dapat dilakukan secara aktif mengikuti pelajaran, mencari sumber-sumber pembelajaran sesuai dengan pengalaman pembelajarannya.

4. Untuk penelitian yang lebih relevan, disarankan agar aspek kognitif siswa, misalnya intelegensi siswa juga diteliti kontribusinya terhadap hasil belajar matematika jika diberikan model-model pembelajaraan tersebut. 
5. Dalam rangka meningkatkan hasil belajar siswa, diharapkan kepada orang tua agar ikut berpartisipasi dengan aktif dalam memantau dan mengikuti proses belajar anak, hal ini disebabkan tanggung jawab anak pada dirinya masih labil.Sehingga sangat memerlukan bimbingan dan motivasi dilingkungan maupun ditengah keluarganya.

6. Kepada para pengambil kebijakan diharapkan dengan adanya inovasi baru dalam hal pembelajaran yang dilakukan para guru, supaya diberikan dukungan dan motivasi secara memadai. Jika tujuan ini tercapai diharapkan peningkatan mutu pendidikan benarbenar dapat diwujudkan.

\section{Daftar Pustaka}

Arends, R.I (1997). Model-model Pembelajaran Inovatif Berorientasi Konstuktivitis, Jakarta

Arends, R.I. (2001). Exploring Teaching: An Introduction to Education. New. York: Mc Graw-Hill Companies.

Ibrahim, M. 2000. Pembelajaran Kooperatif. Surabaya: University Press.

Lanya, H., Zayyadi, M., \& Aini, S. D. (2020). Mathematic Communication Skills In Senior High School Based On Gender Differences. Pi: Mathematics Education Journal, $3(2), 75-81$.

Mardyastuti, A., Suarni, N. K., \& Parmiti, D. P. (2016). Pengaruh Model Pembelajaran NHT dan Motivasi Berprestasi Terhadap Hasil Belajar IPA Siswa Kelas IV. MIMBAR PGSD Undiksha, 4(2).

Prastiwi, Y. (2013). Penerapan Model Pembelajaran Kooperatif Tipe NHT (Numbered Heads Together) Untuk Meningkatkan Hasil Belajar Siswa di Sekolah Dasar. Jurnal Penelitian Pendidikan Guru Sekolah Dasar, 1(2), 1-10.
Santhi, N. N. A. W., Japa, I. G. N., \& Tegeh, I. M. (2017). Pengaruh Model Pembelajaran Kooperatif Tipe ThinkPair-Share dan Minat Belajar Terhadap Hasil Belajar IPA Siswakelas V di SD Gugus I Sibetankecamatan Bebandem Kabupaten Karangasem Tahun Pelajaran 2016/2017. MIMBAR PGSD Undiksha, 5(2).

Simbolon, A. (2019). Peningkatan Kemampuan Koneksi Matematis Siswa Melalui Pembelajaran Kontekstual dan Kooperatif Tipe STAD. Jurnal THEOREMS (The Original Research of Mathematics), 4(1).

Solekhah, E., \& Murdiana, I. N. (2015). Penerapan Model Pembelajaran Kooperatif Tipe NHT Untuk Meningkatkan Hasil Belajar Siswa Kelas VIII SMP NEGERI 15 Palu pada Materi Penjumlahan dan Pengurangan Pecahan Bentuk Aljabar. Jurnal Elektronik Pendidikan Matematika Tadulako, 2(3), 249-260.

Syarifah, U. L. (2015). Kemampuan Guru Menjelaskan dalam Pembelajaran Tematik Berbasis KTSP di SD Kecamatan Ngaliyan Kota Semarang (Doctoral dissertation, Universitas Negeri Semarang).

Qalsum, U. (2020). Peningkatan Hasil Belajar Bahasa Indonesia Melalui Model Pembelajaran Kooperatif dengan Tipe Numbered Heads Together (NHT) Siswa Kelas VII. C SMP Datok Sulaiman Palopo pada Materi Teks Narasi (Cerita Imajinasi). Jurnal Onoma: Pendidikan, Bahasa, dan Sastra, 6(1), 481-497.

Zayyadi, M. (2016). Pengaruh Strategi Pembelajaran Peningkatan Kemapuan Berpikir (SPPKB) Terhadap Hasil Belajar Matematika Siswa SMP 1 Pamekasan. Jurnal Pendidikan Fisika, (Akses 15 Mei 2016). 
Fatah, Pembelajaran Kooperatif dengan | 155

Zayyadi, M., \& Maulana, W. H. (2016). Profil Berpikir Siswa Sekolah Menengah Kejuruan dalam Memecahkan Masalah Matematika
Ditinjau dari Gender. In Prosiding Seminar Nasional Pendidikan Matematika. 